\title{
Coaxial treatment chamber for liquid food treatment through pulsed electric field
}

\author{
Rai Naveed Arshad ${ }^{1}$, Zulkurnain Abdul-Malek ${ }^{2}$, Mohd. Hafizi Ahmad ${ }^{3}$, Zolkafle Buntat ${ }^{4}$, Z. Nawawi $^{5}$, \\ C L G Pavan Kumara ${ }^{6}$, Asaad Zuhair Abdulameer ${ }^{7}$, M.A.B. Sidik ${ }^{8}$ \\ 1,2,3,4,6,7 Institute of High Voltage and High Current, School of Electrical Engineering, Faculty of Engineering, \\ Universiti Teknologi Malaysia, Malaysia \\ ${ }^{5,8}$ Department of Electrical Engineering, Faculty of Engineering, Universitas Sriwijaya, Indonesia
}

\begin{tabular}{|c|c|}
\hline Article Info & ABSTRACT \\
\hline Article history: & ver the last couple of decades, pulsed electric field (PEF) attained \\
\hline Received Jan 3, 2020 & $\begin{array}{l}\text { substantial consideration in the food industry with an effort to generate } \\
\text { replacements to conventional thermal treatment. It is recognized to produce }\end{array}$ \\
\hline Revised Mar 25, 2020 & secure and chill-stable liquid food samples with fresh and nutritional \\
\hline Accepted Apr 5, 2020 & $\begin{array}{l}\text { qualities. The uniform electric field in the treatment zone has been } \\
\text { recognized as the main handling parameter. The design of the treatment }\end{array}$ \\
\hline Keywords: & $\begin{array}{l}\text { chamber shows an important impact on the effectiveness of the procedure by } \\
\text { controlling homogenous treatment. This study revealed the homogeneity of }\end{array}$ \\
\hline Coaxial electrodes & the electric field strength of the different existing treatment chambers \\
\hline COMSOL Multiphysics & $\begin{array}{l}\text { througn } \\
\text { treatment chamber for continuous treatment of liquid samples. This research }\end{array}$ \\
\hline Liquid food & helps to adopt some fundamental designing steps for a new treatment \\
\hline Pulsed electric field & chamber with a uniform distribution of the electric field. \\
\hline
\end{tabular}

Copyright $(2020$ Institute of Advanced Engineering and Science. All rights reserved.

\section{Corresponding Author:}

Rai Naveed Arshad, Institute of High Voltage and High Current, School of Electrical Engineering, Universiti Teknologi Malaysia, 81310 UTM Johor Bahru, Malaysia.

Email: rainaveed@yahoo.co.uk

\section{INTRODUCTION}

Nowadays, a large number of buyers need fresh-like foodstuffs, particularly liquid foods [1-3]. Thus, keeping the unique flavour, colour qualities and high nutritive quality during the treatment is demanding significantly. Conventionally, the deterioration of microbes is executed by thermal procedures. However, it yields modifications to the flavour and taste along with nutrient damage. One of choice to the usual techniques, PEF is concentrated on as a non-thermal protection strategy used in the pasteurization process to an effectively inactive microbial cell in the liquid foods [4-7]. Generally, PEF treatment systems contain treatment chambers, pulse power modulator, sample-handling and monitoring systems [5-6, 8]. The treatment chamber is utilized to hold electrodes as well as an enclosure to contain a food product [9-10]. It offers a high voltage towards food products through a couple of electrodes. Hence, designing of the treatment chamber is an essential feature in the growth of the PEF treatment system.

The PEF technology can be required intended for liquid food to enhance shelf life. As a way to meet this kind of demand, various laboratories, educational research institutions and groups happen to be planned, developed, produced and also utilized PEF treatment chambers for non-thermal of fruit juice [8, 11]. The design of the treatment chamber was progressively developed from static to continuous. Within the static chambers, a bunch of food samples is treated as a product using revealing all the fluids to the treatment zone within a chamber [12]. On the other side, the continuous chambers treat moving liquid samples from the 
treatment zone in a very stable mode through a pump motor [13-14]. The chamber configuration displays a critical impact on the efficiency of the methodology by influencing treatment uniformity, the maximum value of the field, and product quantity [15]. The challenge is to outline a mechanical design of a chamber equipped for working at uniform electric field intensities without dielectric breakdowns [16]. Figure 1 shows crosssectional views of a different configuration of electrodes in the design of the treatment chambers for liquid food processing. Parallel plate chambers provide homogenous treatment but mostly display poor treatment uniformity. The parallel configuration of electrodes produces a field improvement problem at the edges, and co-linear electrodes overestimated the actual exposure of the electric fields inside the treatment area [17-18]. Hence, the combination of coaxial electrodes provides an almost uniform pulsed electric field.

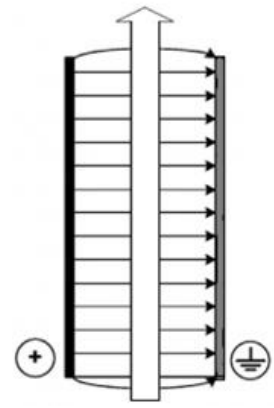

(a)

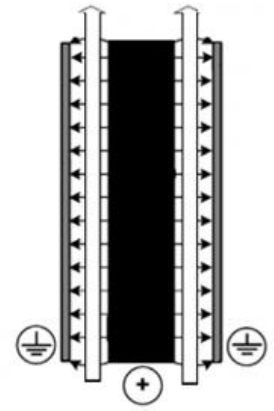

(b)

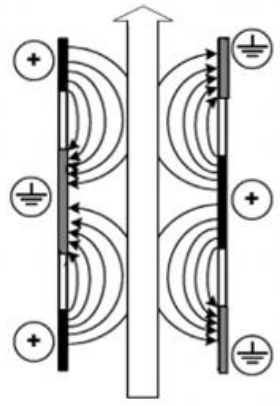

(c)

Figure 1. Cross-sectional views of arrangements of treatment chambers; (a) parallel plate,

(b) Co-axial, (c) Collinear

The co-axial chamber is composed of two hollow cylinders with the direction of the electric field directed radially, whereas the flow moves axially. Inside this chamber, the dispersion of the electric fields is non-homogeneous from the internal towards the external cylinder [19]. However, the higher the radius of the electrodes (at a given gap), the more homogeneous is the distribution of electric fields. As the impedance of the load (treatment chamber with some sample) is affected by liquid food and also amends the applied high voltage pulses. Different impedance for various foods is an inevitable obstacle to the examination of the PEF treatment system and can be overcome by using a coaxial chamber [2]. The internal electrode of the coaxial chamber permits adjustments at several values of resistivity [20-21]. This configuration can be operated at higher electric field intensities with less rise in temperature of treated material [22-23]. There is a need to direct future research towards continuous mode to meet industrial uptake. However, this will require substantial funding and research collaboration to support this research scope.

Some fundamental steps are required to consider the geometrical designing of any treatment chamber. After designing, it's mandatory to analyze it through some simulation study. This paper discusses some design issues and compares the uniformity of the electric field to some earlier designed treatment chamber before and compare them with our new strategy of the continuous coaxial treatment chamber. This comparison included uniformity of the treatment chamber for the applied electric field by COMSOL Multiphysics

\section{COMSOL MULTIPHYSICS MODEL}

Computer simulation has developed a necessary part of research and development. A simulation environment is simply an interpretation of actual physical laws into their computer-generated form. COMSOL Multiphysics is a computational software that permits scholars to precisely simulate with numerous diverse conditions. A particular model can integrate with several physical properties of the system. The researcher creates the geometry, chooses materials for each part of the geometry, and applies the suitable Physics study to the design. Initially, it generates meshes of the geometry, which is a web of multiple points. Later on, these points are used to calculate the physical results from the selected study. It also facilitates parameters sweep and user-defined variables for alterations in the systems.

The AC/DC module is used in the study of the electric fields in the treatment chamber. It facilitates the application of electric potentials, charges, and grounds to geometries. This module governs by the classical electrostatics, conservation of charge, and Coulomb's Law. Thus it facilitates to study the electric 
fields and potential electric fields with plots and graphs. The following two equations demonstrate the charge conservation and classical electrostatics in AC/DC Electrostatics module,

$$
\begin{aligned}
& E=-\nabla V \\
& \nabla \cdot D=\rho f
\end{aligned}
$$

where ' $E$ ' is the electric field strength $(\mathrm{kV} / \mathrm{cm})$, ' $\mathrm{V}$ ' is the applied voltage $(\mathrm{kV})$, ' $\mathrm{D}$ ' is the electric displacement field $\left(\mathrm{C}-\mathrm{m}^{-2}\right)$, and ' $\rho \mathrm{f}^{\prime}$ ' is the free electric charge density (i.e., number of free charges per unit volume). Selection of the materials and modify accordingly of treatment chambers, which was performed by the data used in the research. It is recommended to mesh the design with the minimum conceivable size to permits COMSOL execution in a reasonable time interval. Usually, 3D models consume more memory and time resources than the 2D model. Similarly, the symmetric design is easy to simulate than an asymmetric one. A stationary study is only required when the variables under consideration are time-independent and

\section{RESULTS AND DISCUSSION}

In this section, it is explained the results of research and at the same time is given the comprehensive discussion. The discussion is done in the following sub-sections.

\subsection{Continuous treatment chamber}

Static chambers can only process a given volume of liquid food at a time, for experimental applications. However, a dynamic chamber qualifies continuous processing for industrial application [24]. Normally, The treatment chambers for PEF treatment of continuous flowing liquids were evolved based on the static treatment chamber [20]. Alkhafaji, in 2007, has designed a treatment chamber for continuous flowing liquid treatment, as shown in Figure 2(a). Figure 2(b) shows the electric field distribution through COMSOL. It shows that near the corners of the electrode and the chamber body, the electric field strength was more than the treatment region.

During treatment, a cooling system is also used to keep up the sample liquid inside the calculated temperature value [25]. Therefore, Pizzichemi has proposed a coaxial treatment chamber with liquid flowing inside the high voltage electrodes to overcome the heating effects at the surface of the electrodes, as shown below in Figure 3. Additionally, as the resistance of the chamber is sample dependent so it is a limitation in the design of the treatment chamber. The internal electrode of the coaxial chamber permits adjustments at several values of resistivity [20-21]. This design contained a movable inner electrode that could permit us to adjust too many estimations of resistivity.

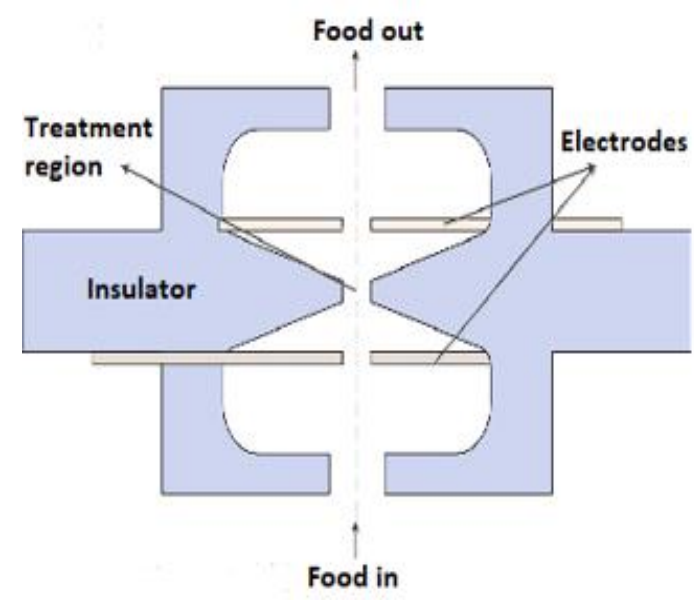

(a)

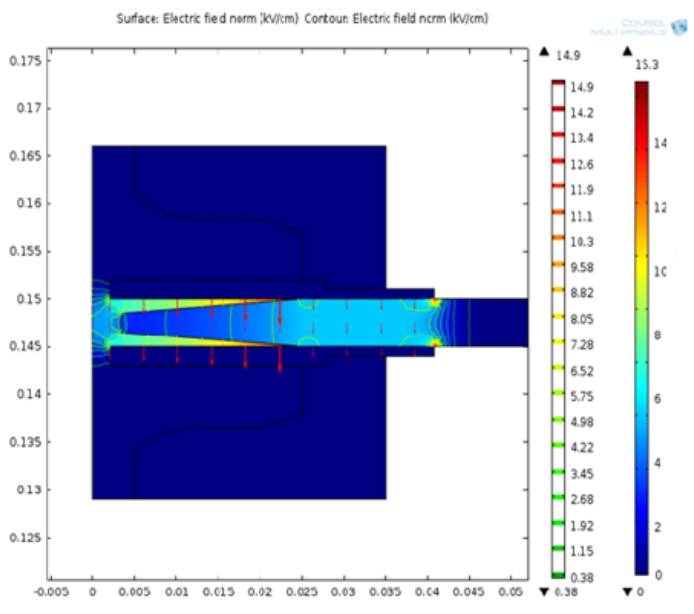

(b)

Figure 1. Treatment chamber designed by Alkhafaji [21], (a) solid work model, (b) distribution of electric fields 


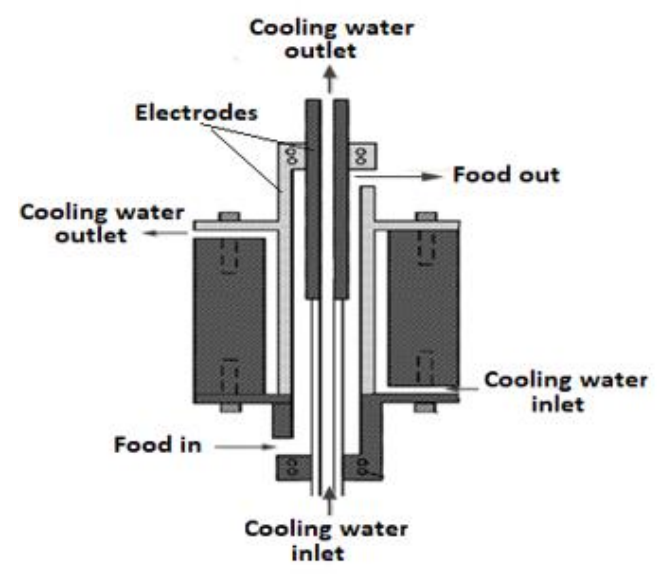

(a)

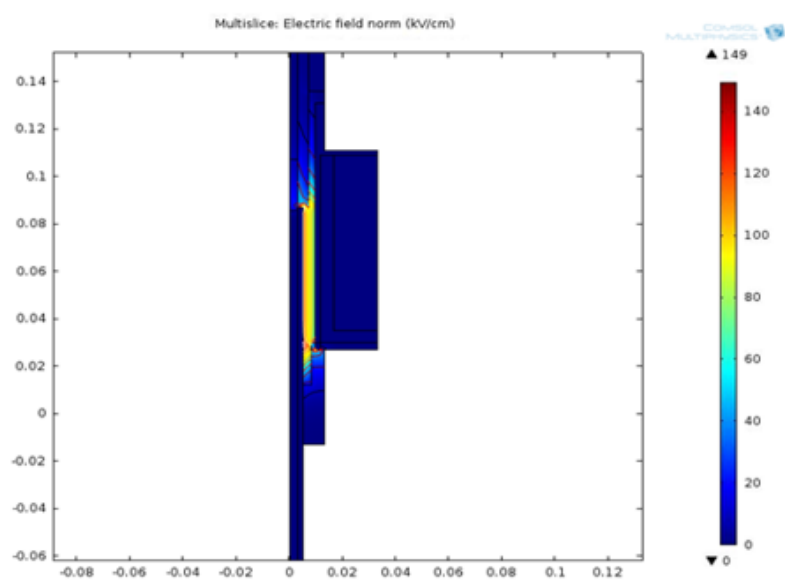

(b)

Figure 2. (a) Coaxial chamber with coolant system by Pizzichemi's design [18], (b) Distribution of electric field

\subsection{Designing methodology}

Accurate measurements of the treatment chamber are essentially required for estimation of the homogenous distribution of the electric field within the treatment region. For coaxial shaped electrode configuration, the electric field strength is the highest near the region of the electrode connected to the high voltage supply. The field strength inside at any location ' $r$ ', such that $R_{1}<\mathrm{r}<R_{2}$, is given by the following equation:

$$
\mathrm{E}=\frac{V}{\operatorname{rln}\left(\frac{R_{2}}{R_{1}}\right)}
$$

where ' $r$ ' is the radius of the circle upon which an electric field is measured. ' $R_{1}{ }^{\prime}$ and ' $R_{2}{ }^{\prime}$ are the radii of the internal and external electrode surface, individually. In spite of the non-homogeneous distribution of the electric fields, this sort of treatment chamber got broad consideration because of its straightforward setup and homogeneous fluid flow.

\subsection{Simulation results}

For the PEF treatment of liquid food, some geometries of the continuous treatment chambers are studied in this research. Based on the earlier designs of the treatment chambers, optimization of the treatment parameters has been done to attain superior performance of the PEF treatment. This design ensures the higher resistance and minimum variations in the electric field intensities for orange juices. There is no corner of the electrodes that cause increasing the uniformity of the applied electric field strength. It helps to further investigation of the treatment chamber not only with coaxial but others as well.

Figure 3 depicts that the variation in the electric field reduces with the increase in the radii of the electrodes. On the other side, (3) is only valid for the case where radii are not too much than the length of the chamber. For the given design, the peak electric field intensity is $13.33 \mathrm{kV} / \mathrm{cm}$, and the least intensity is $11.11 \mathrm{kV} / \mathrm{cm}$. Thus the utmost variation of intensity within the treatment region is $2.2 \mathrm{kV} / \mathrm{cm}$. It's relatively easy to design a pulsed power supply at the lower output voltage.

The electrical impedance of the treatment chamber controls the output pulse of the pulse generator. Dimensional characteristics of the electrodes and the electrical conductivity of liquid are the main parameters responsible for the electrical resistance. The electrical characteristics of electrodes are also affected by some other physical properties of the electrodes such as surface roughness and contamination by biological materials such as protein or fat deposits [26]. For collinear chamber configurations, numerical simulations and the experimental measurement of the voltage and current can be used to determine resistance [27]. For medium-size volumes, coaxial treatment chambers can effectively produce precise characterized electric field distribution [28]. A treatment chamber containing a liquid food sample can be modelled through a parallel combination of resistance and a capacitor [29]. A single resistance can replace this electrical model as the value of resistance is much lower than capacitance. For a coaxial configuration, the equivalent resistance and capacitance can be calculated as: 


$$
\begin{aligned}
& R=\frac{\ln (R o / R i)}{2 \pi \sigma l} \\
& C=\frac{2 \pi \varepsilon o \varepsilon r l}{\ln (R o / R i)}
\end{aligned}
$$

The above equations show that the electrical resistance is controlled by the conductivity ' $\sigma$ ' of the sample, which is a temperature-dependent parameter. However, the conductivity of the sample food undergoes to increase. Table 1 shows the value of electrical conductivities of different liquid samples at different temperatures. Thus, the offer resistance and the required current is also being affected by the temperature of the treated liquid because Hence, electrical resistance can vary from several tens to several hundred amperes in practice and depend on case to case. During this designing, we have used the values of conductivity at $22^{\circ} \mathrm{C}$.

Table 1. Samples conductivity (s/cm) with temperature [29]

\begin{tabular}{ccccc}
\hline Liquid Sample & $4^{\circ} \mathrm{C}$ & $22^{\circ} \mathrm{C}$ & $30^{\circ} \mathrm{C}$ & $40^{\circ} \mathrm{C}$ \\
\hline Beer & 0.0008 & 0.0014 & 0.0016 & 0.0019 \\
Light Beer & 0.0008 & 0.0012 & 0.0014 & 0.0017 \\
Black Coffee & 0.0014 & 0.0018 & 0.0020 & 0.0024 \\
Coffee with milk & 0.0027 & 0.0036 & 0.0040 & 0.0047 \\
Apple Juice & 0.0019 & 0.0024 & 0.0028 & 0.0033 \\
Grape Juice & 0.0006 & 0.0008 & 0.0009 & 0.0010 \\
Lemonade & 0.0008 & 0.0012 & 0.0014 & 0.0017 \\
Limeade & 0.0009 & 0.0012 & 0.0013 & 0.0016 \\
Orange Juice & 0.0031 & 0.0036 & 0.0043 & 0.0050 \\
Skim Milk & 0.0033 & 0.0051 & 0.0059 & 0.0071 \\
Whole milk & 0.0036 & 0.0053 & 0.0062 & 0.0068 \\
Carrot Juice & 0.0079 & 0.0115 & 0.0128 & 0.0148 \\
Tomato Juice & 0.0119 & 0.0169 & 0.0197 & 0.0237 \\
\hline & & & &
\end{tabular}

In any configuration of electrodes, the cross-sectional controls the current density and the force applied. Therefore, the kind and geometry of the electrode are important for the designing of the electrical system for PEF processing. The applied high voltage generates an electric current flow dependent on the electrical conductivity of the sterilization chamber with media. A current associated with the conductivity of the liquid passes through the chamber at the field applied, thus delivering energy to the liquid. The model of a treatment chamber is the parallel combination of resistance and a capacitor. Since the resistance of the treatment chamber with liquid foods is very low as compared to their capacitance so that load can be considered as a pure resistive. Table 1 shows the measured conductivity of a variety of treated liquid foods with resistances in the respective treatment chamber. For this research, we have selected the conductivity of orange juices.

Figure 4 shows that electrical resistance reduces with an increase in the length of the treatment chamber. Thus, the smaller resistance requires more current from the power supply and produces more problems in the designing of the supply. Furthermore, the electrical resistance of the coaxial treatment chamber also increases with decreases in the radii of the electrodes as shown in Figure 5. However, it is contradictory to the variation of the electric field strength with radii. So we need to decide a proper design to accommodate both of these limitations

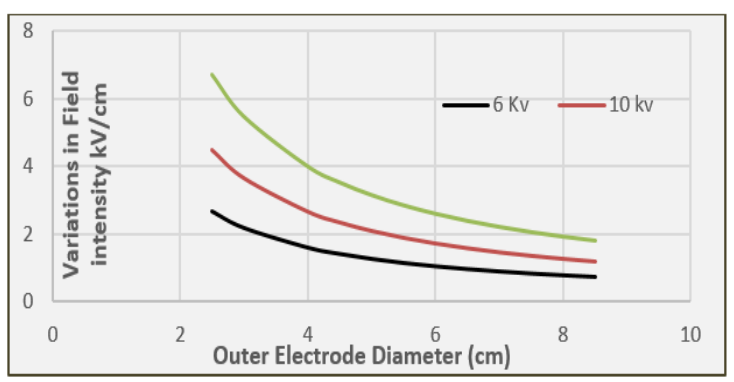

Figure 4. Variation of electric field strength with electrodes gap of $5 \mathrm{~mm}$ and different applied voltages

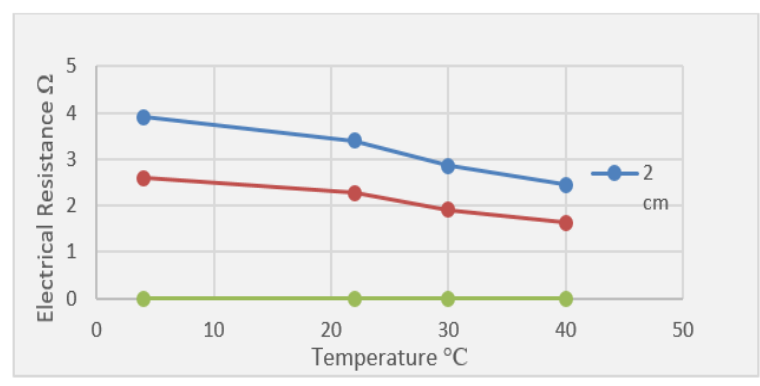

Figure 5. Variation of electrical resistance with the temperature of orange juice in the co-axial chamber at the gap between the electrode also influences the electrical resistance of the coaxial treatment chamber 
However, the larger gap reduces the electric field strength inside the treatment zone. To accommodate this problem, we need to design a pulsed power supply with higher output. Thus it supports to use a gap of $0.5 \mathrm{~cm}$ between the electrodes. Based on the above study, we have designed the following co-axial treatment chamber for liquid food treatment as shown in Figure 6. For the new design, we have decided on the radii of $3 \mathrm{~cm}$ and $2.5 \mathrm{~cm}$ with a length of $3 \mathrm{~cm}$ in the treatment zone as shown in Figure 7 different lengths.

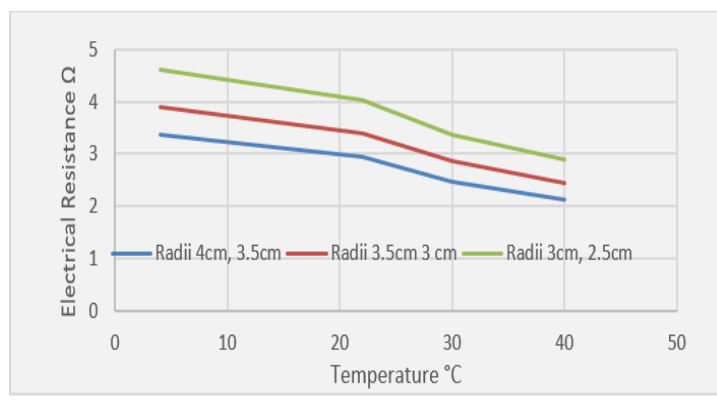

Figure 6. Variation of electrical resistance with the temperature of orange juice at different radii with a gap of $5 \mathrm{~mm}$

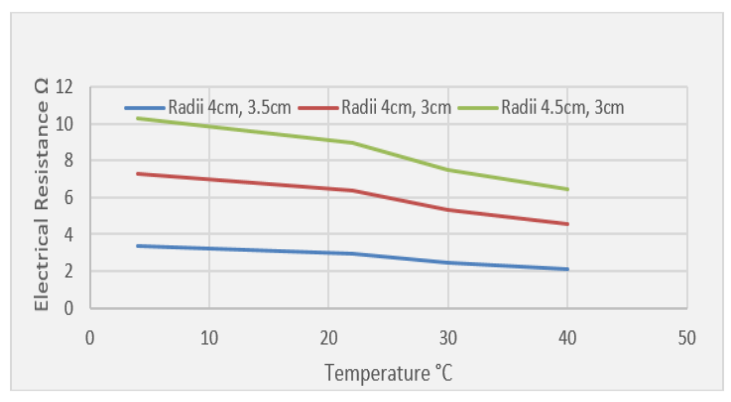

Figure 7. Variation of electrical resistance with a temperature rise of orange juice in the co-axial chamber at a different gap ( $2 \mathrm{~cm}$ length)

For this design, the distribution of the electric field is similar to the other coaxial chambers without any sharp edge as shown in Figure 8. The electrode surfaces were planned to reduce field improvement, intending to escape electrical breakdown. It utilized a suitable design to ensure that the whole sample food could flow inside the treatment zone before exiting the treatment region. It is likewise significant that in this structure, aside from for the consideration of an inlet or outlet port, one end of the coaxial arrangement of action was closed, so field bordering is decreased, which could be further decreased with the correct decision of materials.

The last electrode configuration in the treatment area is outlined in Figure 7. A dielectric material acrylic is utilized to assembly the path for sample flow and hold the electrodes. Both the internal high voltage electrode and the external grounded electrode is designed with stainless steel. In the treatment area, the electrical field distribution was measured by importing this newly designed assembly into COMSOL and the final result is shown in the following Figure 8. Electric field distribution of the newly designed co-axial treatment chamber as shown in Figure 9.

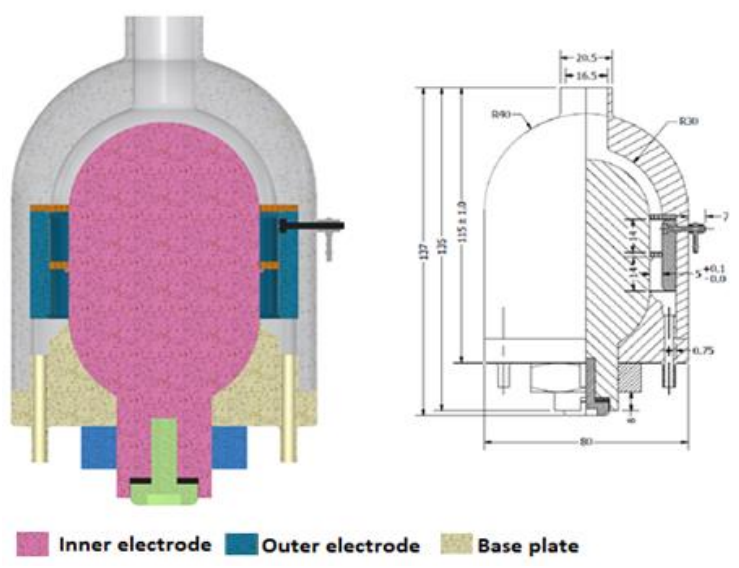

Figure 8. Final dimensions of the coaxial treatment chamber

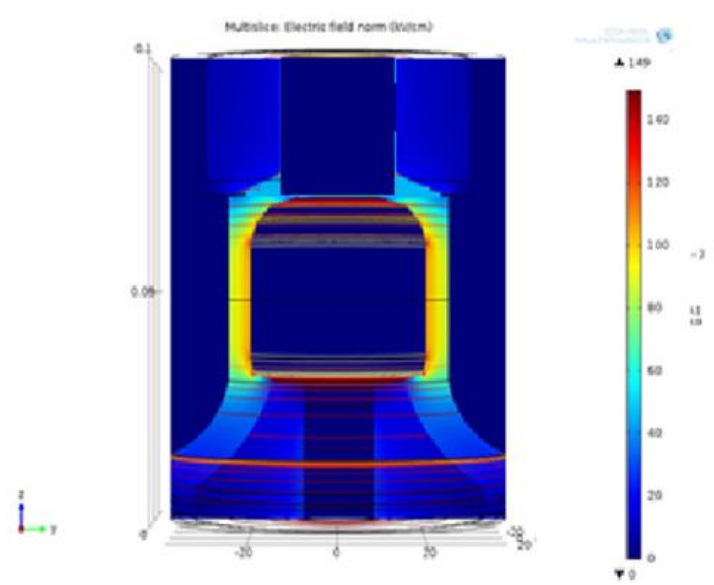

Figure 9. Electric field distribution of the newly designed co-axial treatment chamber

\section{CONCLUSION}

For the PEF treatment of liquid food, some geometries of the continuous treatment chambers are studied in this research. Based on the earlier designs of the treatment chambers, optimization of the treatment 
parameters has been done to attain superior performance of the PEF treatment. This design ensures the higher resistance and minimum variations in the electric field intensities for orange juices. There is no corner of the electrodes that cause increasing the uniformity of the applied electric field strength. It helps to further investigation of the treatment chamber not only with coaxial but others as well.

\section{ACKNOWLEDGEMENTS}

Authors wish to thank the Malaysian Ministry of Education (4F828), Universiti Teknologi Malaysia (18H10 \& 01M44) and Universitas Sriwijaya (4B345 \& 4B279) for financial support.

\section{REFERENCES}

[1] V. D. Bochkov, D. V. Bochkov, I. N. Gnedin, G. M. Vasiliev, V. A. Vasetskiy, and S. A. Zhdanok, "High voltage pulse generator based on TPI-thyratron for pulsed electric field milk processing," 2012 IEEE International Power Modulator and High Voltage Conference (IPMHVC), San Diego, CA, pp. 98-101, 2012.

[2] K. Huang and J. Wang, "Designs of pulsed electric fields treatment chambers for liquid foods pasteurization process: A review," Journal of Food Engineering, vol. 95, no. 2, pp. 227-239, 2009.

[3] S. Toepfl, "Pulsed Electric Field food treatment-scale up from lab to industrial scale," Procedia Food Science, vol. 1, pp. 776-779, 2011

[4] S. Aguilar-Rosas, M. Ballinas-Casarrubias, G. Nevarez-Moorillon, O. Martin-Belloso, and E. Ortega-Rivas, "Thermal and pulsed electric fields pasteurization of apple juice: effects on physicochemical properties and flavour compounds," Journal of Food Engineering, vol. 83, no. 1, pp. 41-46, 2007.

[5] B. Gómez, P. E. Munekata, M. Gavahian, F. J. Barba, F. J. Martí-Quijal, T. Bolumar, et al., "Application of pulsed electric fields in meat and fish processing industries: An overview," Food Research International, vol. 123, pp. 95-105, 2019.

[6] M.-S. Wang, L.-H. Wang, A. E.-D. A. Bekhit, J. Yang, Z.-P. Hou, Y.-Z. Wang, et al., "A review of sublethal effects of pulsed electric field on cells in food processing," Journal of Food Engineering, vol. 223, pp. 32-41, 2018.

[7] U. Roobab, R. M. Aadil, G. M. Madni, and A. E. D. Bekhit, "The Impact of Nonthermal Technologies on the Microbiological Quality of Juices: A Review," Comprehensive Reviews in Food Science and Food Safety, vol. 17, no. 2, pp. 437-457, 2018.

[8] D. Gabrić, F. Barba, S. Roohinejad, S. M. T. Gharibzahedi, M. Radojčin, P. Putnik, et al., "Pulsed electric fields as an alternative to thermal processing for preservation of nutritive and physicochemical properties of beverages: A review," Journal of Food Process Engineering, vol. 41, no. 1, 2018.

[9] M. A. Kempkes, "Industrial Pulsed Electric Field Systems," Springer International, pp. 1-21, 2017.

[10] J. Raso, W. Frey, G. Ferrari, G. Pataro, D. Knorr, J. Teissie, et al., "Recommendations guidelines on the key information to be reported in studies of application of PEF technology in food and biotechnological processes," Innovative Food Science \& Emerging Technologies, vol. 37, pp. 312-321, 2016.

[11] M. Koubaa, F. J. Barba, D. B. Kovačević, P. Putnik, M. D. Santos, R. P. Queirós, et al., "Pulsed electric field processing of fruit juices," in Fruit juices, ed: Elsevier, pp. 437-449, 2018.

[12] G. A. Evrendilek, "Pulsed Electric Field: Impact on Food Product Attributes," in Food Processing Technologies, ed: CRC Press, pp. 407-460, 2016.

[13] J. Raso-Pueyo and V. Heinz, "Pulsed electric fields technology for the food industry: fundamentals and applications": Springer Science \& Business Media, 2010.

[14] Rai Naveed Arshad, Z. B. B. Ali M. Dastgheib, Yanti M. M. Jusoh, Abdullah Munir, Rana Muhammad Aadil, and a. M. H. Ahmad, "Continuous Flow Treatment Chamber for Liquid Food Processing Through Pulsed Electric Field," Journal of Computational and Theoretical Nanoscience, vol. 17, pp. 1492-1498, 2020.

[15] S. Monfort, G. Saldaña, S. Condón, J. Raso, and I. Alvarez, " Inactivation of Salmonella spp. in liquid whole egg using pulsed electric fields, heat, and additives," Food microbiology, vol. 30, no. 2, pp. 393-399, 2012

[16] H. Jäger, "Process performance analysis of pulsed electric field (PEF) food applications," Doktor der Ingenieurwissenschaften, 2013.

[17] R. Buckow, J. Semrau, Q. Sui, J. Wan, and K. Knoerzer, "Numerical evaluation of lactoperoxidase inactivation during continuous pulsed electric field processing," Biotechnology progress, vol. 28, no. 5, pp. 1363-1375, 2012.

[18] H. Bermaki, M. Ziane, A. Semmak, Y. Bellebna, H. Belhassaini, and A. Tilmatine, "Experimental Analysis of Monoaxial And Biaxial Pulsed Electric Field Treatment Chambers For Food Processing," Carpathian Journal of Food Science And Technology, vol. 9, no. 4, pp. 131-141, 2017.

[19] R. N. Arshad, Z. Buntat, M. Sidik, A. Alamgir, Z. Nawawi, and M. Hafizi, "Proficiency of Double-Exponential Pulse Waveform in Food Treatment through Pulsed Electric Field," in 2019 2nd International Conference on High Voltage Engineering and Power Systems (ICHVEPS), Denpasar, Bali, Indonesia, pp. 218-222, 2019.

[20] M. Pizzichemi, "Application of pulsed electric fields to food treatment," Nuclear Physics B-Proceedings Supplements, vol. 172, pp. 314-316, 2007.

[21] S. R. Alkhafaji and M. Farid, "An investigation on pulsed electric fields technology using new treatment chamber design," Innovative food science \& emerging technologies, vol. 8, no. 2, pp. 205-212, 2007.

[22] K. Huang, L. Yu, L. Gai, and J. Wang, "Coupled simulations in colinear and coaxial continuous pulsed electric field treatment chambers," Transactions of the ASABE, vol. 56, no. 4, pp. 1473-1484, 2013. 
[23] H. Masood, Y. Diao, P. J. Cullen, N. A. Lee, and F. J. Trujillo, "A comparative study on the performance of three treatment chamber designs for radio frequency electric field processing," Computers \& Chemical Engineering, vol. 108, pp. 206-216, 2018.

[24] M. Kandušer, A. Belič, S. Čorović, and I. Škrjanc, "Modular Serial Flow Through device for pulsed electric field treatment of the liquid samples," Scientific Reports, vol. 7, no. 8115, pp. 1-12, 2017.

[25] G. A. Evrendilek and Q. Zhang, "Effects of pulse polarity and pulse delaying time on pulsed electric fields-induced pasteurization of E. coli O157: H7," Journal of Food Engineering, vol. 68, no. 2, pp. 271-276, 2005.

[26] M. S. Moonesan and S. H. Jayaram, "Effect of Pulsewidth on Medium Temperature Rise and Microbial Inactivation under Pulsed Electric Field Food Treatment," IEEE Transactions on Industry Applications, vol. 49, no. 4, pp. 1767-1772, 2013.

[27] R. Buckow, P. Baumann, S. Schroeder, and K. Knoerzer, "Effect of dimensions and geometry of co-field and colinear pulsed electric field treatment chambers on electric field strength and energy utilisation," Journal of food engineering, vol. 105, no. 3, pp. 545-556, 2011.

[28] S. H. Jayaram, "Sterilization of liquid foods by pulsed electric fields," IEEE Electrical Insulation Magazine, vol. 16, no. 6, pp. 17-25, 2000.

[29] S. Krishnaveni, R. Subhashini, and V. Rajini, "Inactivation of bacteria suspended in water by using high frequency unipolar pulse voltage," Journal of Food Process Engineering, vol. 40, no. 6, pp. 1-8, 2017. 